九州大学学術情報リポジトリ

Kyushu University Institutional Repository

\title{
Evaluation on Raw Milk Trading System in Inner Mongolia: Based on the Analysis from the Perspectives of Security and Market Efficiency
}

NA, WuYunTa

Faculty of Public Administration post-doctoral research station of Dongbei University of Finance and Economics

MORITAKA, Masahiro

Laboratory of Food Marketing and Distribution, Division of Agricultural and Resource

Economics, Department of Agricultural and Resource Economics, Faculty of Agriculture, Kyushu University

FUKUDA, Susumu

Laboratory of Food Marketing and Distribution, Division of Agricultural and Resource

Economics, Department of Agricultural and Resource Economics, Faculty of Agriculture, Kyushu University

ZHANG Da Xiang

Faculty of Public Administration post-doctoral research station of Dongbei University of Finance and Economics

https://doi.org/10.5109/2339033

出版情報：九州大学大学院農学研究院紀要. 64 (2)，pp.387-394，2019-09-02. Faculty of Agriculture, Kyushu University

バージョン :

権利関係 : 


\title{
Evaluation on Raw Milk Trading System in Inner Mongolia - Based on the Analysis from the Perspectives of Security and Market Efficiency
}

\author{
WuYunTa NA ${ }^{1}$, Masahiro MORITAKA, Susumu FUKUDA* and Xiang Da ZHANG ${ }^{1}$ \\ Laboratory of Food Marketing and Distribution, Division of Agricultural and Resource Economics, \\ Department of Agricultural and Resource Economics, Faculty of Agriculture, \\ Kyushu University, Fukuoka, 819-0395, Japan \\ (Received May 7, 2019 and accepted May 8, 2019)
}

\begin{abstract}
The paper focuses on Principle of One Village and One Enterprise issued with the opportunity of "Melamine Milk Powder Incident". It evaluates the change of trading competition model in raw milk market from the perspective of safety assurance and market efficiency. Main conclusion in the paper is: it can drive dairy enterprises to conduct the monitoring provided that social supervision is intensified under the situation that buyers of raw milk situate at the competition of monopolistic market so as to prevent from melamine interfusion. And monopolistic competition naturally forms within the region and it shall not occur with the harms brought by monopolistic competition. Concerning this point, Principle mandatorily divides purchase bases of raw milk for different dairy enterprises, harm with monopolistic competition shall not take place on the divided bases. That is to say, as long as social surveillance is strengthened, it can effectively assure product safety, and market efficiency shall not be largely damaged as well.
\end{abstract}

Key words: Principle of One Village and One Enterprise, Evaluation Safety, Game theory

\section{INTRODUCTION}

The development of dairy industry is affirmed as effective mode to promote the development of national economy and solve 「issues concerning agriculture, countryside and farmers $\rfloor$ by the state in China. In particular, dairy industry is vital local industry in Inner Mongolia. On June 11, 2018, General Office of State Council printed Opinions on Promoting the Prosperity of Dairy Industry and Securing Quality Safety of Dairy Products, comprehensively deployed to speed up the prosperity of dairy industry and guarantee quality safety of dairy products. Therefore, healthy and sustainable development of dairy industry plays a crucial role of driving local economy of Inner Mongolia.

In recent years, issues of food safety often occur all around the country, Principle of One Village and One Enterprise and Principle of One Village and One Product as the solutions were launched all over the country. Thus, it gradually forms the pattern division of one village and one enterprise which produce one kind of featured products. What change does the issuance of such policies brings in market structure? What kind of social effect does it take? It needs verify.

After the breakout of "Melamine Milk Powder Incident", the government of Inner Mongolia Autonomous Region issued Implementation Opinions on Promoting Sustainable Healthy Development of Dairy Industry (No. [2008] 106). It subsequently strengthens the supervision and management of raw milk production and circulation links. The Opinions regulates that all dairy farmers can only supply raw milk to one dairy enterprise, supplying places of raw milk for dairy enterprises shall be divided. That is the system enforcement named Principle of One Village and One Enterprise. Concerning the changes of trading mode in future raw milk dairy market and its influence on the economy by the issuance of Principle, it is necessary for us to analyze and evaluate the effect on raw milk trading mode by the implementation of new system from the perspective of safety assurance and market efficiency.

Before analytical model is illustrated, existing associated researches shall be firstly stated. Tian Guanghua (2010) made theoretical analysis on safety regulations and management of milk and dairy products. Analytical models illustrated by Baoyindureng (2006) and Kong Xiangzhi etc. (2010) mainly focus on benefit distribution between dairy enterprises and dairy farmers. However, these researches have not involved in how to restrain from the recurrence of the event through the new system with the opportunity of "Melamine Milk Powder Incident" and how to assess the new system.

Based on the deficiency of current researches and the severity of urgent problems to be solved, this paper focuses on Principle of One Village and One Enterprise, the system takes waning and waxing problem between safety assurance and market efficiency as hypothetical proposition. It verifies the influence on safety assurance and market efficiency due to the changes caused by the construction of trading competition model of raw milk by Principle of One Village and One Enterprise.

Analysis method creates one model of two kinds of trading as "trading mode that private milk station exists in 2 dairy enterprises and 1 dairy enterprise" and analyzes with "non-cooperative game theory".

\footnotetext{
1 Faculty of Public Administration post-doctoral research station of Dongbei University of Finance and Economics

* Corresponding author (E-mail: sufukuda@agr.kyushu-u.ac.jp)
} 


\section{RAW MILK TRADING BEFORE THE ISSUANCE OF NEW SYSTEM}

\section{Model construction}

In this section, the behaviors of melamine infusion in private milk station and supervision of dairy enterprises with extensive form game before the issuance of new system is analyzed. Because raw milk suppliers in Inner Mongolia are scattered dairy farmers, in the model, firstly, it assumes that supply mode of raw milk consists $\mathrm{n}$ dairy farmers in 1 village without milk station. Secondly, buyers in raw milk trading market of Inner Mongolia are duopoly competition, so raw milk purchase in 2 dairy enterprises is classified as Bertrand model that oligopoly firms with homogeneous products takes the prices as decision variable competition. About dairy enterprise $i=1,2$ its supply function is represented by $q\left(p_{i} \mid p_{j}\right)$. Supply function of entire village is set as $q\left(\max \left(p_{i}, p_{j}\right)\right), \frac{\partial_{q(p)}}{\partial_{p}}>0$

$$
\begin{aligned}
& q\left(p_{i} \mid p_{j}\right)= \begin{cases}q\left(p_{i}\right) & \text { when } p_{i}>p_{j} \\
q\left(p_{i}\right) / 2 & \text { when } p_{i}=p_{j} \\
0 & \text { when } p_{i}<p_{j}\end{cases} \\
& (i, j=1,2 \quad i \neq j)
\end{aligned}
$$

Purchase prices that 2 dairy enterprises simultaneously offer for dairy farmers are represented as $p_{i}, p_{j}$ raw milk collected from dairy farmers by private milk station is set as $q\left(\max \left(p_{i}, p_{j}\right)\right)$. The rest deducting the expenses of production selling management from the cost of raw milk represents with $p_{m}$. $k$ is investment scale of private milk station, $\beta$ is checkout rate of foreign matters from dairy enterprise, $\gamma$ is social exposure rate. From the above, analysis model construction in the paper is shown as Fig. 1.

Here, there are 4 strategies for private milk station to collect raw milk, (1) raw milk from dairy enterprise 1 and dairy enterprise 2 is interfused with melamine, (2) raw milk only in dairy enterprise 1 is interfused with melamine, (3) raw milk only in dairy enterprise 2 is interfused with melamine, (4) no melamine is interfused in two dairy enterprises. For example, private milk station interfuses melamine with raw milk from two dairy enterprises. When it is checked out by dairy enterprise, milking expense $C\left[\left(q\left(p_{1}\right)+q\left(p_{2}\right)\right), k\right]$ in milk station becomes loss. If it is not checked out by dairy enterprise, it flows into the market, $\left[\left(q\left(p_{1}\right)+q\left(p_{2}\right)\right](1+\theta)\right.$ obtains superior profit. However, is assumptive watered ratio of private milk station, and it is classified as nondiscovery by dairy enterprise. Under the situation that dairy enterprise checks out melamine, monitoring expense $C\left(\beta_{i}\right)(i=1,2)$ becomes loss. If it flows into the market, the income of raw milk for dairy farmer and milking income for private milk station should not become loss considering from social exposure rate $\gamma_{\text {before }}$ Earning equation $\pi_{s}$ of private milk station is indicated as (2). Likewise, earning equations for other 3 strategies are indicated as (3), (4), (5).

$$
\begin{gathered}
\left.\pi_{s}\right|_{\text {Interfusion for both } 2}=\left(1-\beta_{i}\right) w(1+\theta) \\
{\left[q\left(p_{1}\right)+q\left(p_{2}\right)\right]-C\left[\left(q\left(p_{1}\right)+q\left(p_{2}\right)\right), k\right]} \\
\left.\pi_{s}\right|_{\text {Interfusion for 1 }}=w q\left(p_{2}\right)+\left(1-\beta_{i}\right) \\
w(1+\theta) q\left(p_{1}\right)-C\left[\left(q\left(p_{1}\right)+q\left(p_{2}\right)\right), k\right] \\
\left.\pi_{s}\right|_{\text {Interfusion for 2 }}=w q\left(p_{1}\right)+\left(1-\beta_{i}\right) \\
w(1+\theta) q\left(p_{2}\right)-C\left[\left(q\left(p_{1}\right)+q\left(p_{2}\right)\right), k\right] \\
\left.\pi_{s}\right|_{\text {Non-interfusion for 2 }}=w\left[q\left(p_{1}\right)+q\left(p_{2}\right)\right] \\
-C\left[\left(q\left(p_{1}\right)+q\left(p_{2}\right)\right), k\right]
\end{gathered}
$$

Comparing Equation (2) (5), it can be seen that private milk station shall not interfuse with melamine when checkout rate of dairy enterprise is $\beta_{i} \geq \frac{\theta}{1+\theta}$. Hence, monitoring standard of dairy enterprise below is set as $\bar{\beta}_{i} \geq \frac{\theta}{1+\theta}$, the standard without monitoring is set as $\underline{\beta}_{i}=0$, game tree with extensive form game is shown as Fig.1. Participants in the game are private milk station and dairy enterprise, the game which is extended

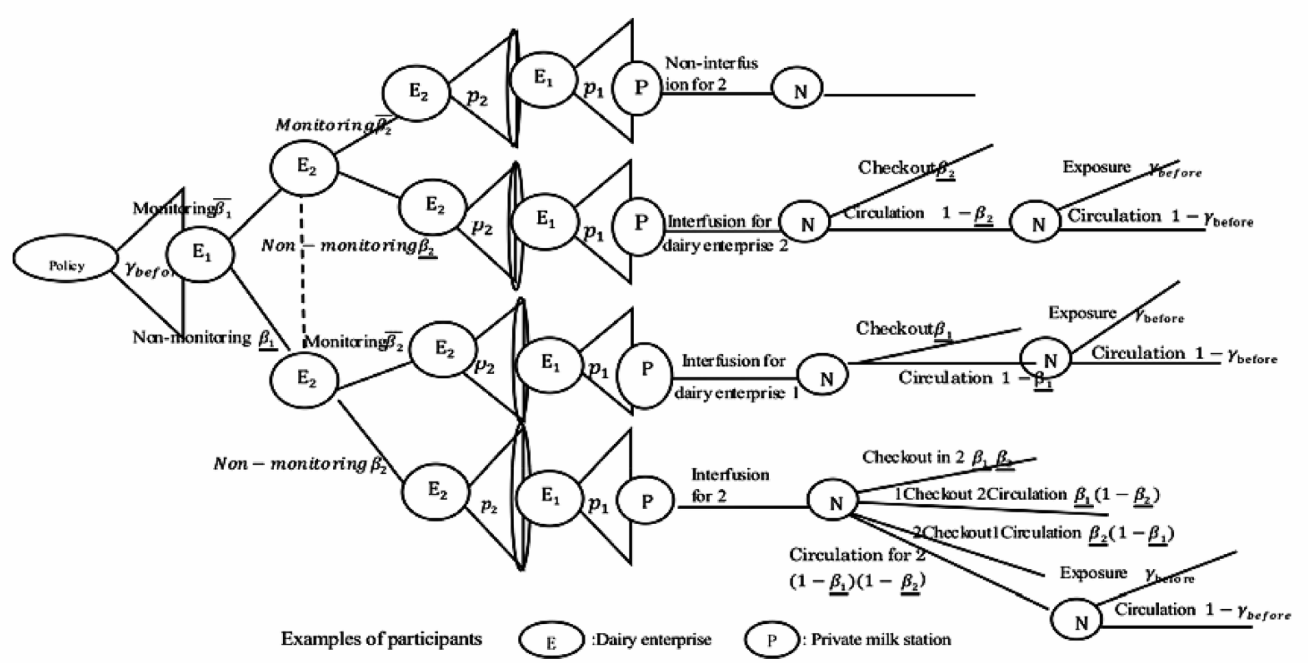

Fig. 1. Game Tree of Raw Milk Trading before the Issuance of New System. 
from left to right makes branch description in time series. It is explained in time series below, firstly, it should determine whether dairy enterprise conducts the monitoring or not from the strategy, secondly, it should consider from three perspectives as raw milk purchase price $p$ prompted dairy farmer, earning of dairy enterprise from raw milk purchasing, processing and selling, and it is set as the maximum. Next, the behavior of private milk station is set as interfusion with melamine or without melamine. The earning of private milk station is set as milking earning and it is set as the maximum.

\section{Analysis}

Situation of 2 dairy enterprises with monitoring $\left(\bar{\beta}_{1}\right.$ $\left.=\frac{\theta}{1+\theta}, \bar{\beta}_{2}=\frac{\theta}{1+\theta}\right)$

When checkout rate of dairy enterprise is $\bar{\beta}_{i}=\frac{\theta}{1+\theta}$ $(i=1,2)$ as it is previously explained that 2 dairy enterprises conduct the monitoring, private milk station shall not adulterate. Earning function $\pi_{m i}(i, j=1,2 \quad i \neq j)$ of dairy enterprise is indicated as Expression (6).

$$
\begin{array}{r}
\left.\max _{p_{i}} \pi_{m i}\right|_{\left(\bar{\beta}_{i}, \bar{\beta}_{j}\right)}=\left(p_{m}-p_{i}-w\right) q_{i}\left(p_{i} \mid p_{j}\right)-c\left(\frac{\theta}{1+\theta}\right) \\
(i, j=1,2 \quad i \neq j)
\end{array}
$$

Next, trading price is solved on the condition of both 2 dairy enterprises with monitoring. According to supply function in Expression (1), purchase price $p_{j}$ of raw milk for dairy enterprise $j(i, j=1,2 \quad i \neq j)$, earning function of dairy enterprise $i$ can be expressed as follows.

$$
\left.\pi_{m i}\right|_{\left(\bar{\beta}_{i}, \bar{\beta}_{j}\right)}=\left\{\begin{array}{rr}
\left(p_{m}-p_{i}-w\right) q\left(p_{i}\right)-c\left(\frac{\theta}{1+\theta}\right), \\
\text { when } p_{i}>p_{j} \\
\frac{1}{2}\left(p_{m}-p_{i}-w\right) q\left(p_{i}\right)-c\left(\frac{\theta}{1+\theta}\right), \\
\text { when } p_{i}=p_{j} \\
-c\left(\frac{\theta}{1+\theta}\right), & \text { when } p_{i}<p_{j}
\end{array}\right.
$$

The earning is (Expression (7)) when other dairy enterprise increases the price, earning is indicated as (Expression (8)) when it offers the same price as other party. Respective earning function is indicated as Fig. 2. Moreover, $p_{0}$ in the Figure is the price when dairy enterprise makes monopolistic purchase (referring to WuYunTaNa et al. (2012 a)).



Fig. 2. Earning Function of Dairy Enterprise with Monitoring Note: referring to Figure 2 in WUYUNTANA et al. (2012 a).
Here, when $p_{i}<p_{j}$ raw milk supply quantity in dairy enterprise $i$ becomes zero, therefore, earning of dairy enterprise becomes zero, therefore, earning of dairy enterprise $i$ turns in to $-c\left(\frac{\theta}{1+\theta}\right)$, it only occurs with monitoring cost. Under such situation, the price that the earning of dairy enterprise $i$ is just zero is set as $\left(\left.\underline{p}_{i}\right|_{p i=}\right.$ $\left.{ }_{p j},\left.\bar{p}_{i}\right|_{p i=p j}\right)$. Because $\left.\underline{p}_{i}\right|_{p i>p j}$ and $\left.\underline{p}_{i}\right|_{p i=p j}$. here are not optimum reactions of enterprise $i$ next, analyze the competition between dairy enterprises with the emphasis on

$\left.\bar{p}_{i}\right|_{p i>p j}$ and $\left.\bar{p}_{i}\right|_{p i=p j}$. However, $\left.\bar{p}_{i}\right|_{p i>p j}+\frac{c\left(\frac{\theta}{1+\theta}\right)}{q\left(p_{\mathrm{i}}\right)}$

$=p_{m}-w$ and $\left.\bar{p}_{i}\right|_{p i>p j}+\frac{c\left(\frac{\theta}{1+\theta}\right)}{q\left(p_{\mathrm{i}}\right)}=p_{m}-w$, so $\left.\bar{p}_{i}\right|_{p i>p j}$

$>\left.\bar{p}_{i}\right|_{p i=p j}$.

When dairy enterprise $j$ prompts purchase price $p_{j}$ response equation of maximum earning in dairy enterprise $i$ can be solved as follows.

$$
p_{i}\left(p_{j}\right) \begin{cases}=p_{o} & \text { when } p_{j} \leq p_{o} \\ =p_{j}+\varepsilon & \text { when } p_{o}<p_{j}<p_{m}-w \\ =p_{j} & \text { when } p_{j}=p_{m}-w \\ <p_{j} & \text { when } p_{j}>p_{m}-w\end{cases}
$$

It can be seen from Expression (11) that it might monopolize the market if one party slightly increases purchase price in the procedure that respective purchase prices in 2 dairy enterprises rise up to $p_{m}-w$ However, if purchase price is higher than $p_{m}-w$, it may become loss. Hence, the only optimal intersection $\left(p_{1}^{*}\right.$, $\left.p_{2}^{*}\right)=\left(p_{m}-w, p_{m}-w\right)$ between 2 dairy enterprises is equilibrium warning line. At the point, earning $-c\left(\frac{\theta}{1+\theta}\right)$ of 2 dairy enterprises can be obtained from Fig.2.

Situation of only 1 dairy enterprise with monitoring $\left(\bar{\beta}_{1}=\right.$ $\frac{\theta}{1+\theta}, \underline{\beta_{2}}=0$ )

Here it takes dairy enterprise 1 with monitoring and dairy enterprise 2 without monitoring as analytic object. Optimum reaction of dairy enterprise 1 with monitoring is indicated as Expression (10) (13). However, because the mode of dairy enterprise 2 without monitoring is different, its mode is deduced as follows. Firstly, any purchase price $p_{1}$ of dairy enterprise 1 to earning function of dairy enterprise 2 is indicated as follows. Simultaneously, $c\left(\beta_{2}\right)=0$.

$$
\left.\pi_{m 2}\right|_{\left(\bar{\beta}_{1}, \underline{\beta}_{2}\right)}=\left\{\begin{array}{r}
{\left[\left(1-\gamma_{\text {before }}\right) p_{m}-p_{2}-w\right] q\left(p_{2}\right),} \\
\text { when } p_{2}>p_{1} \\
\frac{1}{2}\left[\left(1-\gamma_{\text {before }}\right) p_{m}-p_{2}-w\right] q\left(p_{2}\right) \\
\text { when } p_{2}=p_{1} \\
\text { when } p_{2}<p_{1}
\end{array}\right.
$$

Here, the earning with the price higher than other dairy enterprise (Expression (14)) is 2 times more than the earning with the same price as other dairy enterprise (Expression (15)). Respective earning functions are indicated as Fig.3. It can be seen from Fig. 3 that response equation of maximum earning in dairy enterprise 2 is solved as follows when dairy enterprise prompts purchase price $p_{1}$. 


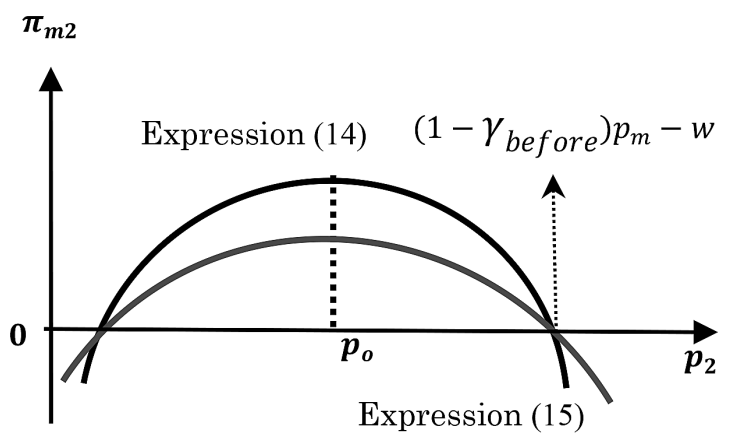

Fig. 3. Earning Function of Dairy Enterprise without Monitoring Note: referring to Figure 2 in WUYUNTANA et al. (2012 a).

$p_{2}\left(p_{1}\right) \begin{cases}=p_{o} & \text { when } p_{1} \leq p_{0} \\ =p_{j}+\varepsilon & \text { when } p_{o}<p_{1}<\left(1-\gamma_{\text {before }}\right) p_{m}-w \\ =p_{j} & \text { when } p_{1}=\left(1-\gamma_{\text {before }}\right) p_{m}-w \\ <p_{j} & \text { when } p_{1}>\left(1-\gamma_{\text {before }}\right) p_{m}-w\end{cases}$

Here, it can be seen that how far competitive warning line of 2 dairy enterprises rely on purchase price increasing. For example, as it is indicated in optimum reaction Expression (10) (13) for dairy enterprise with monitoring, in order to regain monitoring expenses to the greatest extent, it shall compete between purchase price $\left.\bar{p}_{1}\right|_{p 1>p 2}$ for earning which is exactly zero and high price $p_{m}-w$. Upper limit of price competition for dairy enterprise 2 without monitoring is illustrated as Expression (17) (20) as $\left(1-\gamma_{\text {before }}\right) p_{m}-w$. However, the size of upper-limit price $\left(1-\gamma_{\text {before }}\right) p_{m}-w$ for dairy enterprise 2 without monitoring and purchase price $\bar{p}_{1} \mid$ $p 1>p 2$ for dairy enterprise with earning which is exactly zero determine competitive warning line of 2 dairy enterprises (referring to WuYunTaNa et al. (2012 a)).

If $\left(1-\gamma_{\text {before }}\right) p_{m}-w$ compares with Expression

$\left.\bar{p}_{1}\right|_{p 1>p 2}+\frac{c\left(\frac{\theta}{1+\theta}\right)}{q\left(p_{1}\right)}=p_{m}-$ here, when $\gamma_{\text {before }} \geq$ $\frac{c\left(\frac{\theta}{1+\theta}\right)}{p_{m} q\left(\left.\bar{p}_{1}\right|_{p 1>p 2}\right)},\left(1-\gamma_{\text {before }}\right) p_{m}-w \leq\left.\bar{p}_{1}\right|_{p 1>p 2}$. When $\gamma_{\text {before }}$ $<\frac{c\left(\frac{\theta}{1+\theta}\right)}{p_{m} q\left(\left.\bar{p}_{1}\right|_{p 1>p 2}\right)},\left(1-\gamma_{\text {before }}\right) p_{m}-w>\left.\bar{p}_{1}\right|_{p 1>p 2}$. Hence, next, separate $\gamma_{\text {before }} \geq \frac{c\left(\frac{\theta}{1+\theta}\right)}{p_{m} q\left(\left.\bar{p}_{1}\right|_{p 1>p 2}\right)}$ from $\gamma_{\text {before }}<$ $\frac{c\left(\frac{\theta}{1+\theta}\right)}{p_{m} q\left(\left.\bar{p}_{1}\right|_{p 1>p 2}\right)}$ and solve equilibrium warning line of 2 dairy enterprises.

(a)When $\gamma_{\text {before }} \geq \frac{c\left(\frac{\theta}{1+\theta}\right)}{p_{m} q\left(\left.\bar{p}_{1}\right|_{p 1>p 2}\right)}$, because dairy enterprise 2 without monitoring can only offer purchase price as $\left(1-\gamma_{\text {before }}\right) p_{m}-w$ in price competition, dairy enterprise 1 prompts competition price $p_{1}=\left(1-\gamma_{\text {before }}\right)$ $p_{m}-w+\varepsilon<\left.\bar{p}_{1}\right|_{p 1>p 2}$ The results turn into unilateral purchase of raw milk for dairy enterprise 1 with monitor- ing. Superior profit $\left.\pi_{m 1}\right|_{p 1>p 2}>0$ is obtained. However, earning of dairy enterprise 2 is zero.

(b) When $\gamma_{\text {before }}<\frac{c\left(\frac{\theta}{1+\theta}\right)}{p_{m} q\left(\left.\bar{p}_{1}\right|_{p 1>p 2}\right)}$, and dairy enterprise 2 without monitoring wins in purchase competition of raw milk, earning of dairy enterprise 1 with monitoring is negative earning $-c\left(\frac{\theta}{1+\theta}\right)$. On the contrary, even if dairy enterprise 1 wins, dairy enterprise 1 makes price competition with the price $\left.\bar{p}_{1}\right|_{p 1>p 2}$ higher than the price that earning becomes 0 , hence, earning of dairy enterprise 1 is lower than zero. On the other hand, purchase quantity of dairy enterprise 2 is zero, so the earning is also zero.

In addition, it can make the same analysis for dairy enterprise 1 without monitoring and dairy enterprise 2 with monitoring, analysis process is omitted here.

The situation that 2 dairy enterprises without monitoring $\left(\beta_{1}=0, \underline{\beta}_{2}=0\right)$

When both 2 dairy enterprises do not conduct the monitoring, the behaviors of 2 dairy enterprises are the same as the behavior of dairy enterprise 2 without monitoring when $\lceil 2$. Only one dairy enterprise with monitoring $\lrcorner$. Hence, optimum reactions of 2 dairy enterprises as $p_{i}\left(p_{j}\right) \quad(i, j=1,2 \quad i \neq j)$ are indicated as Expression (17) (20).

It is the same as the situation of 2 dairy enterprises with monitoring, it can be seen from Expression (18) that respective purchase prices of 2 dairy enterprises are rising up to $\left(1-\gamma_{\text {before }}\right) p_{m}-w$, if the purchase price of one party is slightly higher than other party, it is possible to monopolize the market. However, if purchase price is higher than $\left(1-\gamma_{\text {before }}\right) p_{m}-w$, it shall become loss. Therefore, the only optimum intersection $\left(p_{1}^{*}, p_{2}^{*}\right)=((1$ $\left.\left.-\gamma_{\text {before }}\right) p_{m}-w,\left(1-\gamma_{\text {before }}\right) p_{m}-w\right)$ between two dairy enterprises becomes equilibrium warning line. At this point, earning of 2 dairy enterprises becomes 0 from Expression (19).

Nash equilibrium of 2 dairy enterprises

Concerning 2 dairy enterprises with monitoring or without monitoring, it simultaneously solves Nash equilibrium from the earning of various above-mentioned situations. Here the standard of social exposure rate $\gamma_{\text {before }}$ influences on the success or failure of 2 dairy enterprises, and controls the equilibrium, so it respectively discusses $\gamma_{\text {before }} \geq \frac{c\left(\frac{\theta}{1+\theta}\right)}{p_{m} q\left(\left.\bar{p}_{1}\right|_{p 1>p 2}\right)}$ and $\gamma_{\text {before }}<$ $\frac{c\left(\frac{\theta}{1+\theta}\right)}{p_{m} q\left(\left.\bar{p}_{1}\right|_{p 1>p 2}\right)}$ Game matrixes after earning of dairy enterprises 1, 2 in each situation are shown as Table 1 and Table 2. In which, the left is earning number of dairy enterprise 1 , the right is earning number of dairy enterprise 2.

On the precondition of the choice of other dairy enterprise, dairy enterprise shall take action which can maximize its earning. Under such situation, it shall have 2 Nash Equilibriums, i.e. if one dairy enterprise selects to conduct the monitoring, other dairy enterprise shall 
Table 1. Earning Matrix of 2 Dairy Enterprises at High Exposure Rate

\begin{tabular}{cccc}
\hline & Dairy enterprise 1 \\
\hline \multirow{2}{*}{$\begin{array}{c}\text { Dairy } \\
\text { enterprise } 2\end{array}$} & Monitoring $\bar{\beta}_{1}=\frac{\theta}{1+\theta}$ & Non-monitoring $\underline{\beta}_{1}=0$ \\
\cline { 2 - 4 } & Monitoring $\bar{\beta}_{2}=\frac{\theta}{1+\theta}$ & $-c\left(\frac{\theta}{1+\theta}\right),-c\left(\frac{\theta}{1+\theta}\right)$ & $0, \pi_{m 2}>0$ \\
\hline
\end{tabular}

Payoff: Left is Dairy1 payoff, Right is Dairy2 payoff

Table 2. Earning Matrix of 2 Dairy Enterprises at Low Social Exposure Rate

\begin{tabular}{cccc}
\hline & Dairy enterprise 1 & \\
\hline & Monitoring $\bar{\beta}_{1}=\frac{\theta}{1+\theta}$ & Non-monitoring $\underline{\beta}_{1}=0$ \\
\cline { 2 - 4 } $\begin{array}{c}\text { Dairy } \\
\text { enterprise } 2\end{array}$ & Monitoring $\bar{\beta}_{2}=\frac{\theta}{1+\theta}$ & $-c\left(\frac{\theta}{1+\theta}\right),-c\left(\frac{\theta}{1+\theta}\right)$ & $0 \quad \pi_{m 2}<0$ \\
\cline { 2 - 4 } & Non-monitoring $\underline{\beta}_{2}=0$ & $\pi_{m 1}<0,0$ & 0 \\
\hline
\end{tabular}

Payoff: Left is Dairy1 payoff, Right is Dairy2 payoff

not select the monitoring (Table 1). However, it is expected that both dairy enterprises shall conduct the monitoring for the society. It shall illustrate above-mentioned analysis results below. When purchase price competition of dairy enterprises is considered, it shall drive dairy enterprise to conduct the monitoring if social exposure rate is higher than the rate of monitoring cost to selling income of raw milk in dairy enterprise. However, considering purchase price competition between dairy enterprises and monitoring cost, 2 dairy enterprises shall select to avoid the simultaneous monitoring. Therefore, when one dairy enterprise conducts the monitoring, the equilibrium that other dairy enterprise selects not to conduct the monitoring shall appear. At the moment, there are large possibilities for one party to exit in order to avoid the loss on both sides. It naturally becomes the status of monopolistic competition within the region. Concerning the equilibrium at this time, the behavior without melamine interfusion shall not occur under the monitoring because private milk station is consigned by milking of monopolistic enterprise, therefore, earning in Expression (6) shall be assured.

Under such situation, if the standard of social exposure rate is lower than the rate of monitoring cost of dairy enterprise to selling income of raw milk, the choice that both 2 dairy enterprises don't conduct the monitoring shall be sole equilibrium of dominant strategies.

\section{RAW MILK TRADING AFTER THE ISSUANCE OF NEW SYSTEM}

\section{Model construction}

Because many dairy enterprises are established in Inner Mongolia, the phenomenon that demand exceeds supply of raw milk appears. The fighting for raw milk among dairy enterprises may influence the quality and safety of raw milk.

After the new system issuance, the government divides purchase areas of raw milk for dairy enterprises in order to alleviate the fighting for raw milk. It regulates that raw milk in one village can only supply one dairy enterprise. Moreover, the employees from dairy enterprise often settle in milk station and participate in milking process and sample examination. Even the Departments such as Ministry of Agriculture establish the third committee, supervision standard such as raw milk price fixing has been strengthened (WuYunTaNa, et al. 2012 b).

The model in this section is the same as Model in Section 2. It assumes that the region consists of scattered farmers without milking facilities. The participants are dairy enterprises and private milk stations . However, the purchase of raw milk is restricted to 1 dairy enterprise. Moreover, private dairy station has choice behavior with melamine interfusion or without melamine interfusion. For private milk station, when it takes action of melamine interfusion if it is discovered by dairy enter- 


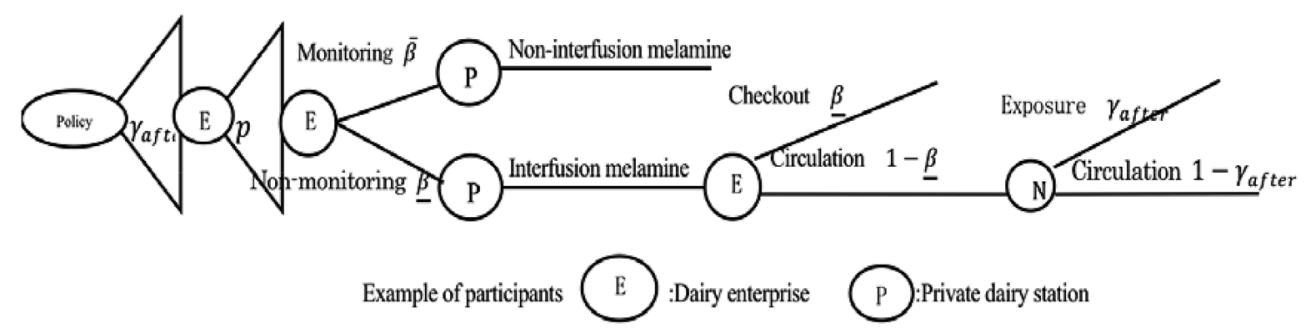

Fig. 4. Raw Milk Trading Game Tree after the Issuance of New System.

prise, milking expense $C[q(p), k]$ shall become loss. If it flows into the market, it shall obtain superior earning, but $\theta$ is the rate of watered milk in private milk station shall be assumed as the standard which can't be found by dairy enterprise.

On the other hand, if dairy enterprise checks out melamine, monitoring expense $C(\beta)$ shall become the loss of the enterprise. If it flows into the market and it is exposed by social supervision standard $\gamma_{\text {after }}$ the expenses of raw milk and milking shall become the loss, it can arrive at normal earning $\pi_{m}$ according to the probability of $1-\gamma_{\text {after }}$.

Based on mark mode of extensive form game, game tree is shown as Figure 4. The behaviors of participants are described from the left to the right.

Firstly, it analyzes optimum action of private milk station with backward induction. When dairy enterprise takes action with melamine infusion or without melamine interfusion, private milk station divides the earnings into Expression (21), (22).

$$
\begin{aligned}
\left.\pi_{s}\right|_{\text {non-interfusion }} & =w q(p)-C[q(p), k] \\
\left.\pi_{s}\right|_{\text {interfusion }} & =(1-\beta) w(1+\theta) q(p)-C[q(p), k]
\end{aligned}
$$

From Expression (21) and (22), it can reach the condition without melamine infusion in private milk station as it is shown below.

$$
\beta \geq \frac{\theta}{1+\theta} \quad(q(p) \neq 0)
$$

Hereinafter, when it conducts the monitoring, checkout rate of dairy enterprise is set as $\bar{\beta}=\frac{\theta}{1+\theta}$, when it doesn't conduct the monitoring, checkout rate is set as $\underline{\beta}=0$ and $c(\underline{\beta})=0$.

Earning modes of dairy enterprise under different circumstances are shown below.

$$
\begin{gathered}
\left.\pi_{m}\right|_{\bar{\beta}}=\left(p_{m}-p-w\right) q(p)-c\left(\frac{\theta}{1+\theta}\right) \\
\left.\pi_{m}\right|_{\underline{\beta}}=\left[\left(1-\gamma_{\text {after }}\right) p_{m}-p-w\right] q(p)
\end{gathered}
$$

\section{Analysis}

On the premise of the choice of private milk station, optimum action of dairy enterprise is formalized. When dairy enterprise conducts the monitoring, purchase price must satisfy following conditions (26) in order to maxi- mize the earning $\left.\pi_{m}\right|_{\bar{\beta}}$, and purchase price p must satisfy following conditions (26).

$$
p \frac{*}{\beta}\left(1+\frac{1}{\eta}\right)=p_{m}-w
$$

Here, $\eta$ is elastic force of raw milk supply price, $\frac{1}{\eta}$ is purchasing power index of buyer. Likewise, when dairy enterprise doesn't conduct the monitoring strictly, purchase price of raw milk is selected as $p$ in order to maximize the earning $\left.\pi_{m}\right|_{\beta}$, hence, the requirement is (27).

$$
p_{\underline{\beta}}^{*}\left(1+\frac{1}{\eta}\right)=\left(1-\gamma_{\text {after }}\right) p_{m}-w
$$

Next, respectively substitute Expression (26) and (27) into Expression (24) and (25), it can obtain monitoring condition equation (28) of dairy enterprise.

$\gamma_{\text {after }} \geq \frac{c\left(\frac{\theta}{1+\theta}\right)-\left\{\left(p_{m}-p_{\bar{\beta}}^{*}-w\right) q\left(p_{\bar{\beta}}^{*}\right)-\left(p_{m}-p_{\underline{\beta}}^{*}-w\right) q\left(p_{\underline{\beta}}^{*}\right)\right.}{p_{m} q\left(p_{\underline{\beta}}^{*}\right)}$

Here, $2^{\text {nd }}$ term of numerator is earning difference under monitoring situation when it is $p_{\beta}^{*}$ and $p_{\beta}^{*}$ For example, when it is defined as $\phi, p_{\bar{\beta}}^{*},\left(p_{m}-p_{\bar{\beta}}^{*}-w\right) \bar{q}\left(p_{\bar{\beta}}^{*}\right)$. shall be maximum value, so $\phi$ is positive number (29).

$$
\phi=\left(p_{m}-p_{\bar{\beta}}^{*}-w\right) q\left(p_{\underline{\beta}}^{*}\right)-\left(p_{m}-p_{\underline{\beta}}^{*}-w\right) q\left(p_{\underline{\beta}}^{*}\right)>0
$$

As it is indicated in Expression (29), if $\gamma_{\text {before }}=$ $\frac{c\left(\frac{\theta}{1+\theta}\right)}{p_{m} q\left(\left.\bar{p}_{1}\right|_{p 1>p 2}\right)}$, is compared with $\gamma_{\text {after }}=\frac{c\left(\frac{\theta}{1+\theta}\right)-\phi}{p_{m} q\left(p_{\underline{\beta}}^{*}\right)}$, $\gamma_{\text {after }}<\gamma_{\text {before }}$ shall be found, establishment condition is 0 $<\phi<c\left(\frac{\theta}{1+\theta}\right)\left[1-\frac{q\left(p_{\underline{\beta}}^{*}\right)}{q\left(\left.\bar{p}_{1}\right|_{p 1>p 2}\right)}\right]$, and establishment condition of $\gamma_{\text {after }} \geq \gamma_{\text {before }}$ is $\phi \geq c\left(\frac{\theta}{1+\theta}\right)[1-$ $\left.\frac{q\left(p_{\underline{\beta}}^{*}\right)}{q\left(\left.\bar{p}_{1}\right|_{p 1>p 2}\right)}\right]>0$.

When $\gamma_{\text {after }}<\gamma_{\text {before }}$, it can drive dairy enterprise to conduct the monitoring if exposure rate is lower than the rate before the issuance of new system, hence, it can effectively prevent from illegal behavior of private dairy station. But buyers of raw milk are monopolistic competition, so purchase price of raw milk shall be lower than 
the price of oligopoly. Therefore, the harm of monopolistic competition shall also appear. The new system is issued with the opportunity of "Melamine Incident", when milk quality is assured, it also weakens market efficiency. So it becomes inherent system with shifting problems. It deserves to emphasize that social exposure rate is not set higher than the rate before the issuance of new system if $\gamma_{\text {after }} \geq \gamma_{\text {before }}$, monitoring action taken by dairy enterprise shall not effectively prevent from illegal behavior of private milk station. Moreover, it is possible to occur with monopolistic harm because buyers of raw milk are monopolistic competition. Hence, under such situation, new system issued with the opportunity of "Melamine Incident" shall become the system which not only can't guarantee the quality of raw milk, but also weaken market efficiency.

\section{CONCLUSION}

The achievements in this paper can be summarized as following points. Firstly, it analyzes the game about purchase price competition between dairy enterprises in the model of 2 dairy enterprises and 1 private milk station before the issuance of new system. If the standard of social exposure rate is higher than the rate of monitoring cost of dairy enterprise to selling income of raw milk, it shall drive dairy enterprises to monitor. However, under such situation, because fierce price competition and monitoring cost of 2 dairy enterprises occur, these 2 dairy enterprises shall avoid simultaneous monitoring action. As a result, the equilibrium shall appear with the exit of dairy enterprise without the monitoring because raw milk is deficient to be gathered. On the other hand, if the standard of social exposure rate is lower than the rate of monitoring cost to selling income of raw milk for dairy enterprises, 2 dairy enterprises don't make monitoring tactics, it shall be sole distribution strategy equilibrium. At the moment, it means it doesn't urge these 2 dairy enterprises to conduct the monitoring because of low social exposure rate. Therefore, it can explain the occurrence of "Melamine Incident" with the equilibrium.

Secondly, the paper testifies that Principle of One Village and One Enterprise does not play a role of assuring the raw milk safety under the situation of one dairy enterprise and 1 private milk station after the issuance of new system. Moreover, if the optimum social exposure rate after the issuance of new system is lower than the rate before the issuance of the new system, there are waning and waxing interior problems of quality safety of raw milk and market efficiency in new system issued with the opportunity of "Melamine Incident". On the contrary, the issuance of new system doesn't play a part in assuring the safety of milk quality and lowers down market efficiency.

In the circulation system of raw milk, private milk station lays a foundation for the occurrence of "Melamine Incident" in 2008 (WuYunTaNa et al. (2012 b)). Under the new system, ascertainment of the interdependence of inter-subjects in raw milk trading mode is indispensable and essential measures when new system is evaluated from the perspective of safety assurance and market efficiency. And such analysis and research shall play a significant role in future healthy and sustainable development of dairy industry in Inner Mongolia.

When raw milk buyer is oligopolistic competition, if it sets very high social exposure rate, the behaviors of the participants are that one dairy enterprise conducts the monitoring, and other dairy enterprise doesn't conduct, then the possibilities of exit become large. Therefore, the competition in the region shall spontaneously turn into monopolistic status. However, there are some rejoining possibilities for exited dairy enterprises, purchase price shall not lower down to the level of monopolistic competition. Therefore, it is not so easy to occur with the monopolistic harms. In this respect, raw milk buyers situate at the monopolistic competition as new system enforces the Principle of One Village and One Enterprise. It can be seen from the results of the paper that it can impel dairy enterprise to take monitoring action only if exposure rate is slightly increased under the same standard. And it can avoid the harms caused by monopolistic competition as well.

The government of Inner Mongolia believes that fierce competition between dairy enterprises shall influence on quality safety of raw milk and dairy products, so Principle of One Village and One Enterprise was issued. However, the results in the paper shows that competition suppression among dairy enterprises may not definitely guarantee the safety of dairy products. It is not necessary to divide purchase areas of raw milk, the safety of dairy products can be guaranteed when social supervision and exposure rate are reinforced. The market efficiency would not be negative influenced enormously. Therefore, it can be concluded that the Principle of One Village and One Enterprise which was issued because of "Melamine Incident" is probably a radical policy. In future, it is necessary to make comprehensive evaluation on above-mentioned similar policies, the results of the research can be taken as theoretical reference basis when the policy is made.

Relative empirical research shall continue to be explored in the future in order to grasp real state of social exposure rate and check-out rate of interfused foreign matters in dairy enterprises after the issuance of new system.

\section{AUTHOR CONTRIBUTION}

WuYunTanNa as the lead researcher of this study identified the research gap and tectonic theory model, to complete the analysis and write-up of this paper. All this WuYunTanNa did is under the academic guidance and supervision from her supervisor Susumu FUKUDA and vice-supervisor Masahiro MORITAKA who both provided critical comments and suggestions on every stage of the research process. Xiang Da ZHANG provided the current state information for the structural theory model. 


\section{REFERENCES}

Baoyindureng, Guo Xiaochuan 2006 Research on Interest Relationship between Dairy Enterprise and Milk Station on Basis of Principle-Agent Theory, Social Science of Inner Mongolia Volume 6

Kong Xiangzhi, Zhang Liyang, Zhong Zhen, Tan Zhixin 2010 Economic Interpretation of Mixing and Adulteration in Milk Station, Research on Organization Model of China's Dairy Economy, China Agricultural Science and Technology Press,. 157-171

Masayoshi Maruyama 1992 Nihon shijo no kyōso k̄̄zō: Shijō to torihiki (Japanese Edition), Sobunsha. , 76-116

Masayoshi Maruyama 1997 Tatsuhiko Nariu, Modern Microeconomics: Applied Micro Theory of Game and Information (Japanese Edition), Sobunsha, 267-288.

Masahiro MORITAKA, Susumu FUKUDA. 2005 Comparative Analysis of Certification System In "The Economic Analysis of Modern Public Policy (Japanese Edition)”, CHUOKEIZAI-SHA HOLDINGS, INC, 151-174.
Qiao Guanghua 2010 Research on Regulations of Dairy Food Safety, China's Dairy Development under Dual CrisisAchievements Collection of China's Dairy Summit Forum in 2009. China Agricultural Science and Technology Press. 107122

WuYunTana, Masahiro MORITAKA, Susumu FUKUDA, 2012 a The Mechanism of the Remaining Private-owned Milking Stations in the Inner Mongolian Fresh Milk Market, Japanese Journal of Food, Agricultural and Resource Economics, 62(2): 23-34

WuYunTana, Susumu FUKUDA, Masahiro MORITAKA 2012b Inner Mongolian Melamine Problem and Changes in the Milk Procurement System, Agricultural Marketing Journal of Japan, 20(4): 24-30

Zhong Zhen · Kong Xiangzhi 2010 Current Status, Efficiency and Quality Safety of Raw Milk of Dairy Station Development, Research on China's Dairy Industry Economic Organization Model, China Agricultural Science and Technology Press, 117-142 